\title{
Chemical technology case study in cemented paste backfill - Newmont's Tanami Gold Mine
}

\author{
R Salter UGC BASF, Australia \\ A Flemmer Newmont Tanami Operations, Australia \\ J Gelson UGC BASF Asia Pacific, Australia \\ Z Martic UGC BASF Global, Switzerland
}

\begin{abstract}
Cemented paste fill operations have been in operation for many years in Australia. In recent years, rapid advances have been made in chemical technologies improving mining backfill operations. BASF's in-depth analysis and laboratory work on both the physical and chemical parameters involved in backfill operations has been instrumental in re shaping this pathway. Many physical parameters can be improved via plant modifications; however, at significant expense to the mine. Even with peak plant performance, further optimisation can only be achieved in a cost-effective manner via improved chemistry. This is where chemical admixtures come into their own.
\end{abstract}

The feed to the backfill plant uses dry excavated tailings. The Tanami plant was unable to operate to the specified solids contents due to variations in chemistry, fineness and high clay content of the tailings, which in turn affected the desired throughput and strength consistency of the fill. Higher cement contents were also required to reliably maintain the desired strengths. The chemical solution proposed by BASF increased solids content, reduced friction and pressures in the pipelines, and maintained a more consistent paste throughput with consistent strengths.

This case study describes the processes employed by BASF for Newmont to identify and resolve issues encountered in the backfill operation at their Tanami Gold Mine. The case study discusses topics from initial sampling, analysis and lab testing to final onsite trials of the chemical admixture solution provided. The benefits to the mine are summarised in the paper.

\section{Introduction}

The Tanami Gold Mine, operated by Newmont, is located in the Tanami Desert in Australia's Northern Territory, about 550 kilometres northwest of Alice Springs. The underground mine has been operational for many years in which it required cemented aggregate fill backfill. The mine later changed to a mining method that did not require backfill for several years. In 2009, the mining method changed again, requiring the need for backfill once again. It was decided that paste fill would be the most economical for the mine utilising dry excavated tailings from the tailings dam some $40 \mathrm{~km}$ from the underground mine. A paste plant was constructed in 2010 and commissioned in November 2011. From the commencement of placing paste, it was identified that the required solids content was unable to be met; therefore, strengths were lower than designed. An increase in binder addition rectified the strength issue, although this came at a considerable cost to the mine. It was identified the problems were due to the high fineness and clay content in the tailings. BASF were engaged to identify a possible chemical solution to achieve desired solids contents, therefore obtaining desired uniaxial compressive strength (UCS) results. Additional requests were to explore rheology control, retention time, water consumption and binder reduction. 


\section{$2 \quad$ Lab trials}

Actual mine site samples of tailings, cement and process water were sent to BASF's technical laboratories in Switzerland, where full analyses and testing could be completed and potential chemical technologies applied for a solution to the backfill problem.

The objectives of the testing were to evaluate the performance and robustness of BASF's proposed admixture solution, as compared to the standard mix design (control), and its effect on flow properties and flow retention time. Further objectives consisted of increasing the solids content while still achieving the same or better flow properties. The final objective was to evaluate possibilities for binder optimisation.

The study included compressive strength development of the backfill samples over time and rheology measurements. Different types of admixtures were used in the study to find the optimum type in terms of performance and economics.

\subsection{Rheology tests}

All backfill material was examined and prepared for testing. Tailings material was dried, disaggregated, homogenised and sampled. All materials were stored at $30^{\circ} \mathrm{C}$ before testing.

Different paste fill designs were used for the testing in order to examine influence of solid content to paste behaviour with different binder contents. Further testing with different types of BASF admixtures followed. The admixture was dosed per tonne of backfill (wet tonne or total backfill). The paste fill was mixed initially at $30^{\circ} \mathrm{C}$ and, after mixing, placed in a room at a temperature of $30^{\circ} \mathrm{C}$. Effectively, the lab was trying to simulate actual stope conditions regarding temperature etc.

Measuring the rheology of the fill was done by measuring yield stress with the Physica MCR 301 instrument with BMC (with the vane sensor ST 59-2V-44.3/120). This is a highly sophisticated and precise instrument with air bearing system measuring head and particularly designed cup to avoid the wall slip effect. Product details available on www.anton-paar.com Additional tests with higher solids content were done using a standard HAAKE VT viscometer in order to obtain yield stress values with the conventional star shaped vane rotor FL100 as well known instrument in backfill practice. Mix designs were adjusted to raise the solids content in order to measure the variation in yield stress because, at lower solids content, torque was too low and instruments with FL100 vane could not record any shear stress (limitation of HAAKE VT viscometer versus Antom Paar rheometer in terms of sensitivity).

All fill samples were mixed as per internal BASF standard procedure, then filled into the measuring cup and measured on the Physica MCR 301 rheometer.

The first round of tests was conducted using the Physica MCR 301 with BMC set-up in control shear stress mode (with HAAKE VT control shear rate mode being used).

From Figure 1 it can be seen that the influence of solid content is major factor determining paste fill behaviour. Namely, with an increase in solid content, yield stress exponentially starts to increase. It can be concluded that from $58 \%$ solids content this magnification in yield stress becomes very important. It can also be noted that binder content has a major influence on paste behaviour. Namely, with higher binder content, paste becomes a less viscous structure as compared to lower cement content paste in the measured range of solids (lower consistency paste), where higher binder content has a lubricating effect to cemented paste fill (CPF) behaviour. 


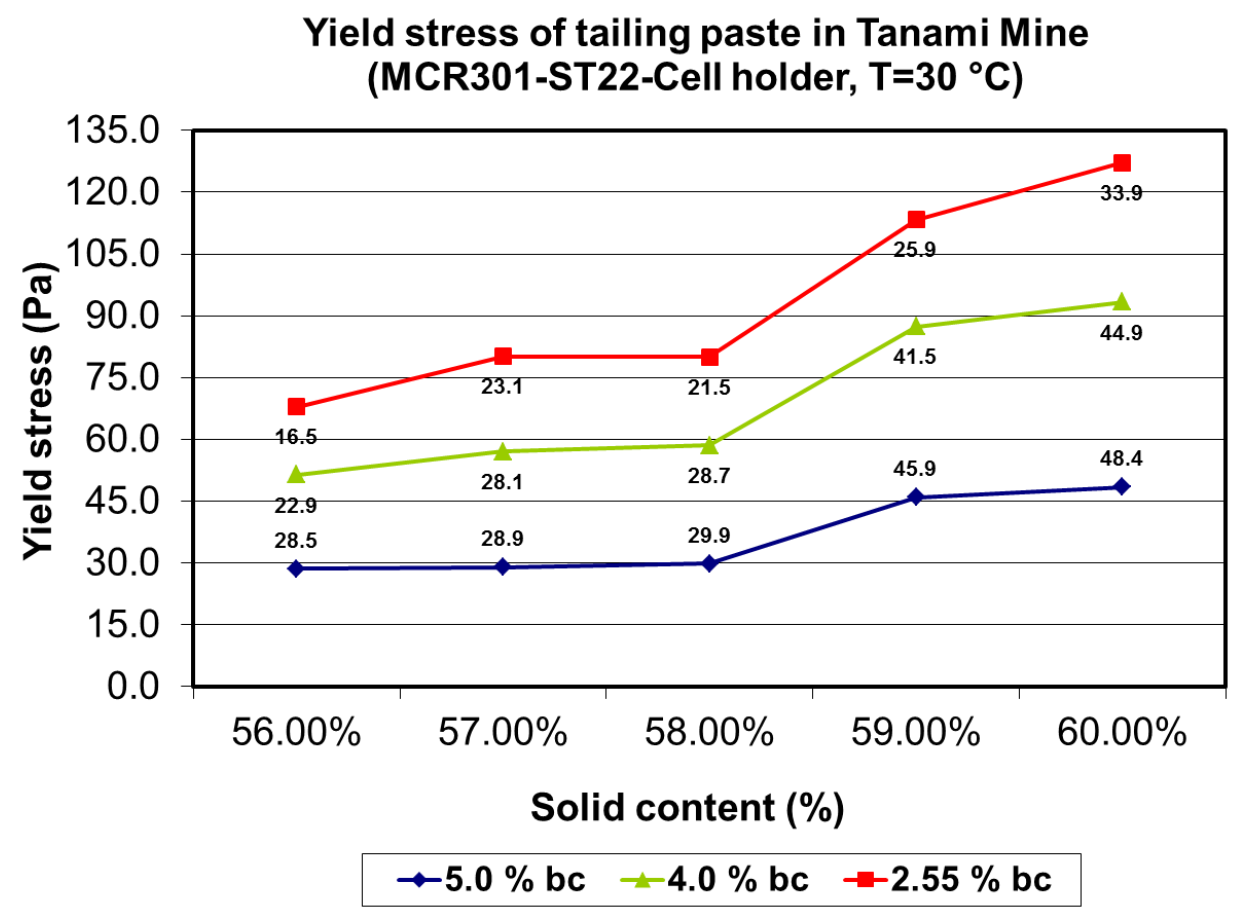

Figure 1 Yield stress versus solid content for 5, 4 and $2.55 \%$ of binder contents mix designs

\subsection{Rheology tests with admixtures}

A series of tests were undertaken in order to determine the influence of BASF admixtures on flow properties of Tanami cemented paste as well as to evaluate possibilities of binder optimisation in order to reduce binder cost and make it more efficient. The vane geometry used for this series of tests is the vane rotor FL100, star shaped with a cub cell. Measurements were taken in control stress mode. Some control tests have been repeated. Reasons for change in instrument use are because there is a smaller amount of material needed for this type of cell and because results are comparable to the HAAKE VT rheometer. 
Yield stress in function of admixture type

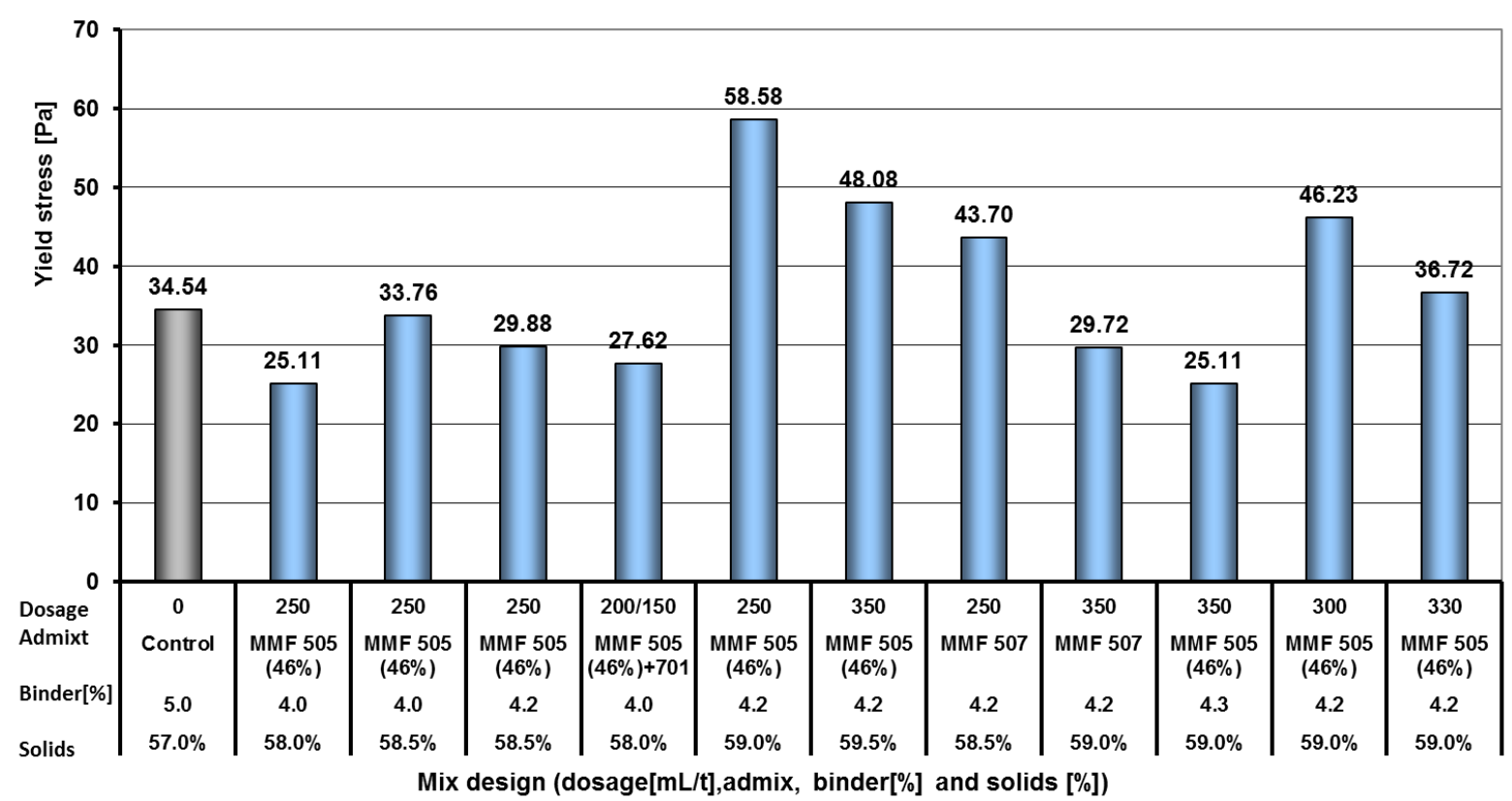

Figure 2 Yield stress as a function of mix design and different admixtures

From Figure 2 it can be seen that BASF admixture MF505C could significantly change rheology of cemented paste fill in sense of yield stress. With admixture MF505C, it should be possible to increase the solid content from 57 to $58.5 \%$ while maintaining the same (or better) flow properties. This has been done in order to evaluate possibilities of optimising binder content of the fill. Initially, it was decided to reduce original binder content from 5 to $4 \%$. As presented in Figure 2, from a rheological point of view, this is feasible with admixture MF505C. Yield stress values using admixtures in all cases were less than control sample, even at higher solids content.

Additional testing was conducted in order to meet UCS requirements. Some tests with higher solids content and some with higher binder content have also been done. It is noticeable that MF505C could change the rheology to meet requested flow properties required for various mix designs. Namely, if we compare the yield stress values of control mix design for $5 \%$ binder at $57 \%$ solids and mix design with MMF505, it can be seen that with higher solids content as compare to control, yield stress is lower. Tests with MMF507 gave some positive results regarding yield stress values but flow retention time was insufficient, as an increase in viscosity was observed during additional mixing (remixing for strength sample preparation). CPF sample apparently lost flowability in short period of time and this admixture have been eliminated in further testing.

\subsection{Rheology test with HAAKE VT}

As mentioned, these tests have been done in order to evaluate fill behaviour and influence of admixtures on this well-known device within a measurable range using the common HAAKE viscometer with a FL100 vane rotor. Even if rheometers that are more sophisticated have been available, a substantial part of testing has been done with the HAAKE VT viscometer because this device and sensor type are widely used and results are comparable. Yield stress measurements with the vane sensor are relative measurements, and change in shape and parameters (especially shear rate) of testing will alter results. Results are presented below. 
Yield stress - HAAKE VT with FL 100 vane star shaped sensor

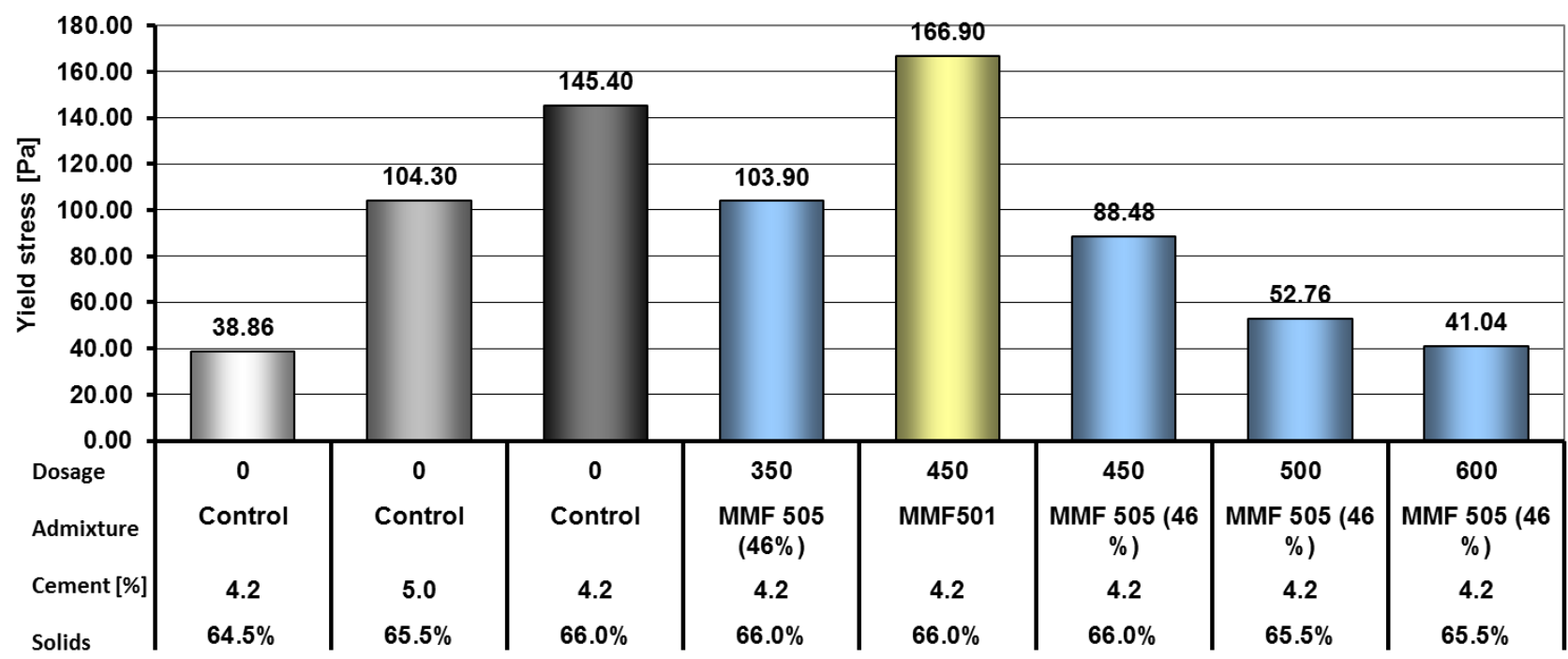

Mix design

\begin{tabular}{|c|c|c|c|}
\hline a64.5\% 4.2 Control 0 & a65.5\% 5.0 Control 0 & a66.0\% 4.2 Control 0 & a66.0\% 4.2 MMF 505 (46\%) 350 \\
\hline 口66.0\% 4.2 MMF 501450 & 口66.0\% 4.2 MMF 505 (46 \%) 450 & 口65.5\% 4.2 MMF 505 (46\%) 500 & a65.5\% 4.2 MMF 505 (46 \%) 600 \\
\hline
\end{tabular}

\section{Figure 3 Yield stress values at elevated solids content measured on HAAKE VT rheometer with star shaped vane rotor}

Figure 3 demonstrates that the yield stress value significantly changes with solids content. This relationship could be described as an 'exponential function'. It could also be seen that in this range of measurement (which is on the boundary in a rheological sense), the performance of MF505C is still significant because the yield stress drops by one third as compared to control. The purpose of these tests was to demonstrate the efficiency of MF505C at a higher solids content of the paste compared to the control mix. 


\subsection{Compressive strength (with admixtures)}

\section{UCS values in function of admixture type and $m x$ design}

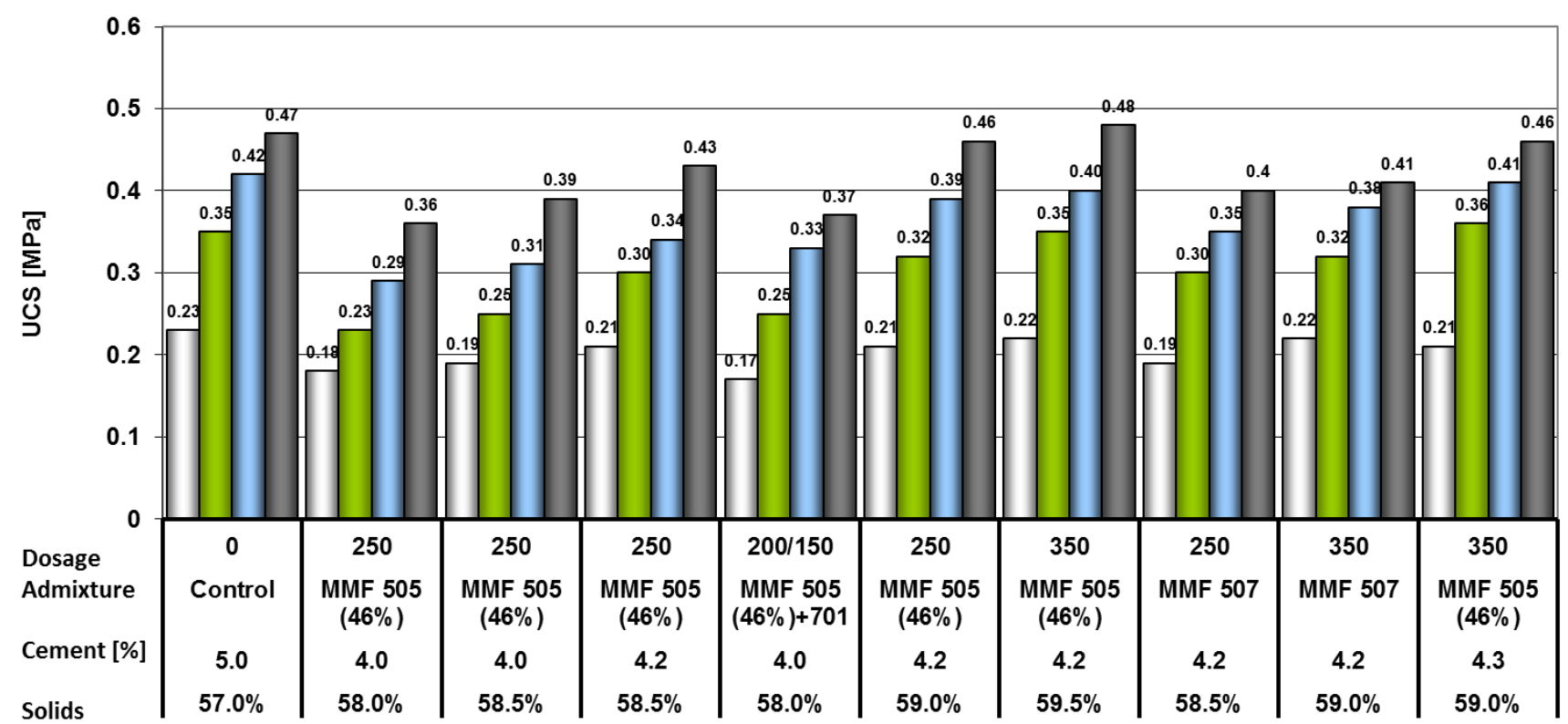

Mix design (dosage[mL/t $]$,admix, binder[\%] and solids [\%])

$\square 7$ day $\square 14$ day $\square 21$ day $\square 28$ day

\section{Figure 4 UCS values of mix designs with BASF admixtures as compared to control sample}

In Figure 4, the UCS strength development is shown over time, measured at 7, 14, 21 and 28 days. As can been seen, the control mix design has higher values than alternative mix designs with lower binder contents. It can be seen that one of the proposed mix designs with $4.2 \%$ binder has a similar strength development as the control mix design with $5 \%$ binder content.

Some further adjustments with admixtures have been undertaken in the development centre in Zurich to improve strength development for this project, and we will hopefully be able to present results of this additional work too.

The adjusted mix design shows that at $59.5 \%$ solids, $4 \%, 2 \%$ binder and $350 \mathrm{~mL} / \mathrm{t}$ dosage of MF505C, the UCS strengths are comparable to the control.

The desired UCS requirements could be achieved, as could the mix using $59 \%$ solids, $4.3 \%$ binder and $350 \mathrm{~mL} / \mathrm{t}$ MF505C. This represents a significant binder reduction of approximately $10-13 \%$.

\subsection{Conclusions from laboratory trials}

From available test results, the admixture MasterRoc MF505C demonstrated superior performance with regard to flowability of the various mix designs compared to the controls. The results documented in this work demonstrate significant influence of MF505C on the rheology of the cemented paste fill in terms of yield stress reduction.

It should be feasible to increase solids content of existing cemented paste fill from actual $57 \%$ solids up to 58.5 (even 59\%) solids. Additional tests showed that the solids content could be raised up to $60 \%$ with increased dose rates of MF505C.

Adjusted mix design showed that it is possible to meet UCS requirements and keep the same flow properties of paste by reducing the amount of binder using MF505C. It could be determined that savings of 
binder will be in the range of $11-13 \%$. The proposed mix designs for $59.5 \%$ of solids, $4.2 \%$ of binder $370 \mathrm{~mL} / \mathrm{t}$ and $59 \%$ of solids, $4.3 \%$ of binder and $330 \mathrm{~mL} / \mathrm{t}$. For practical reasons, a reasonable dosage of admixture in the paste plant will be in the range $400-450 \mathrm{~mL} / \mathrm{t}$.

The admixture demonstrated robustness at elevated temperature and complex water chemistry in terms of workability retention and effectiveness.

\section{$3 \quad$ Field trials}

It was decided by Newmont to proceed with site trials after the encouraging results from the lab trials. Like the lab trials, the objectives of the testing were to evaluate the performance and robustness of MasterRoc MF505C, as compared to the standard mix design (control), and its effect on flow properties and flow retention time. Further objectives included increasing the solids content while still achieving the same or better flow properties, and identifying pressure drop on the paste fill system when the admixtures are added. The final objective was to evaluate possibilities for binder optimisation.

\subsection{Field trial}

Objectives:

- Identify pressure drop in the line when admixture added.

- Investigate the increase in solids to return to operating pressures in pipes.

- Obtain cylinders for UCS results, record slump.

The following parameters were observed:

- A reduction of $539 \mathrm{kPa}$ on pressure sensor PI1020 was recorded with the introduction of MF505C.

- PI1020 sensor dropped from 2,559 to 1,980 kPa.

- Increased solids content of $1.70 \%$ was required to return the pipe pressures to desired pressure of $2,585 \mathrm{kPa}$.

- Solids increase from 62.40 to $64.10 \%$ (recorded from Citect).

- A reduction of $1.1 \mathrm{kPa}$ in borehole friction was recorded with the introduction of MF505C (recorded from Citect).

- Increase in slump of $80 \mathrm{~mm}$ at higher solids content with the introduction of MF505C (higher flow properties with MF505C).

- Pressure sensor readings throughout the pipeline were more consistent with the introduction of MF505C. 
Table 1 Summary of results from field trial MF505C at $2.5 \%$ binder

\begin{tabular}{cccc}
\hline Trial identification & Control & MF505C & MF505C \\
\hline Time & $8: 45 \mathrm{am}$ & $8: 58 \mathrm{am}$ & $9: 01 \mathrm{am}$ \\
Binder content $(\%)$ & 4 & 4 & 4 \\
MasterRoc MF505C (ml/wt) & 0 & 350 & 350 \\
Ambient temp $\left({ }^{\circ} \mathrm{C}\right)$ & 36.3 & 41.2 & 41.2 \\
Paste temp $\left({ }^{\circ} \mathrm{C}\right)$ & 32 & 32 & 32 \\
Slump $(\mathrm{mm})$ & 130 & $\mathrm{~N} / \mathrm{A}$ & 210 \\
Moisture $(\%)$ of tailings & 11.40 & 11.40 & 11.40 \\
Solids $(\%)$ of paste (Citect) & 62.4 & 62.4 & 64.10 \\
P1 pressure (kPa) & 2,559 & 1,980 & 2,585 \\
Borehole friction $(\mathrm{kPa})$ & 8.55 & 7.4 & 6.3 \\
Binder content $(\%)$ & 4 & 4 & 4 \\
\hline
\end{tabular}

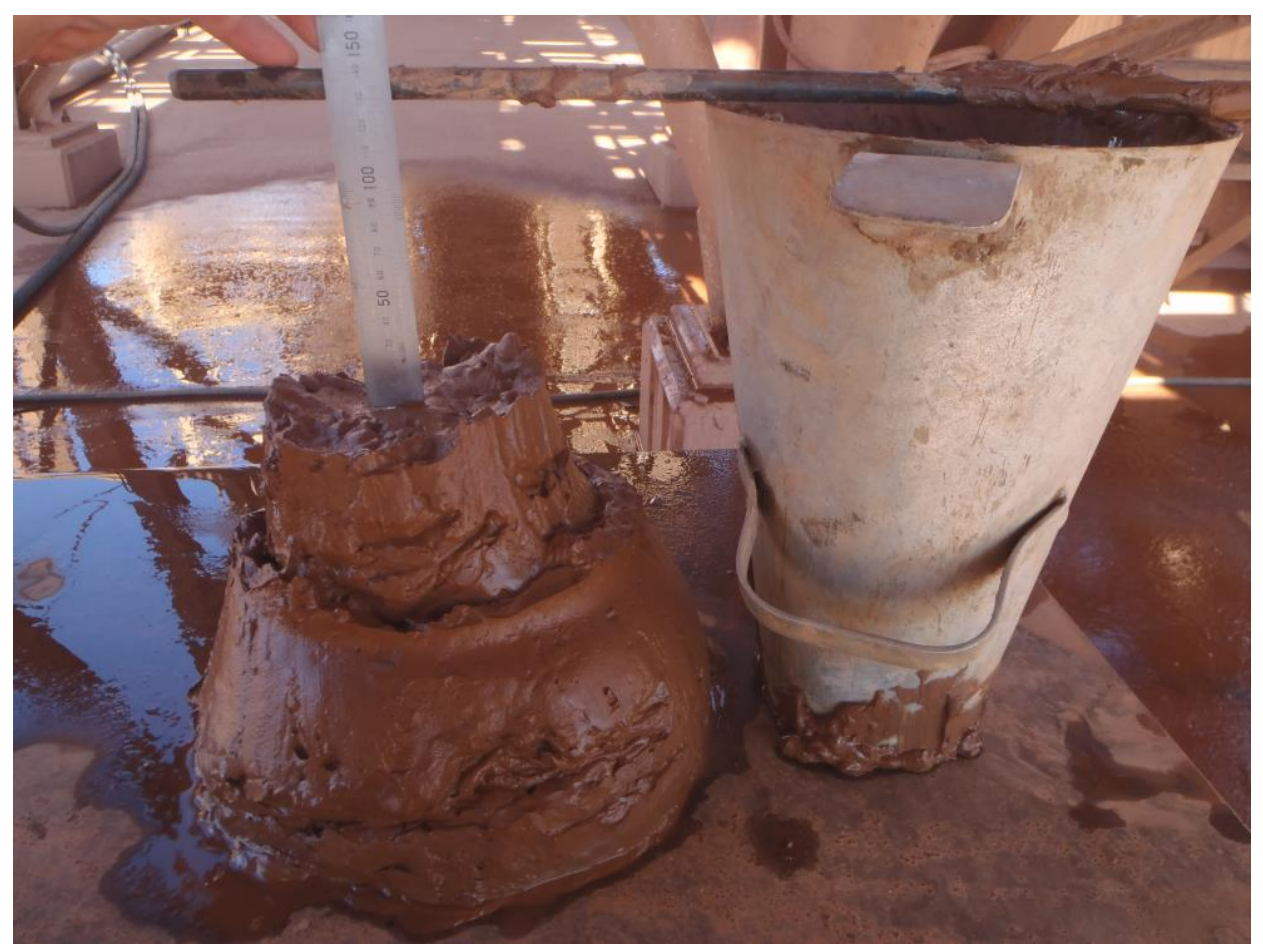

Figure 5 Picture of the control mix, $130 \mathrm{~mm}$ slump 


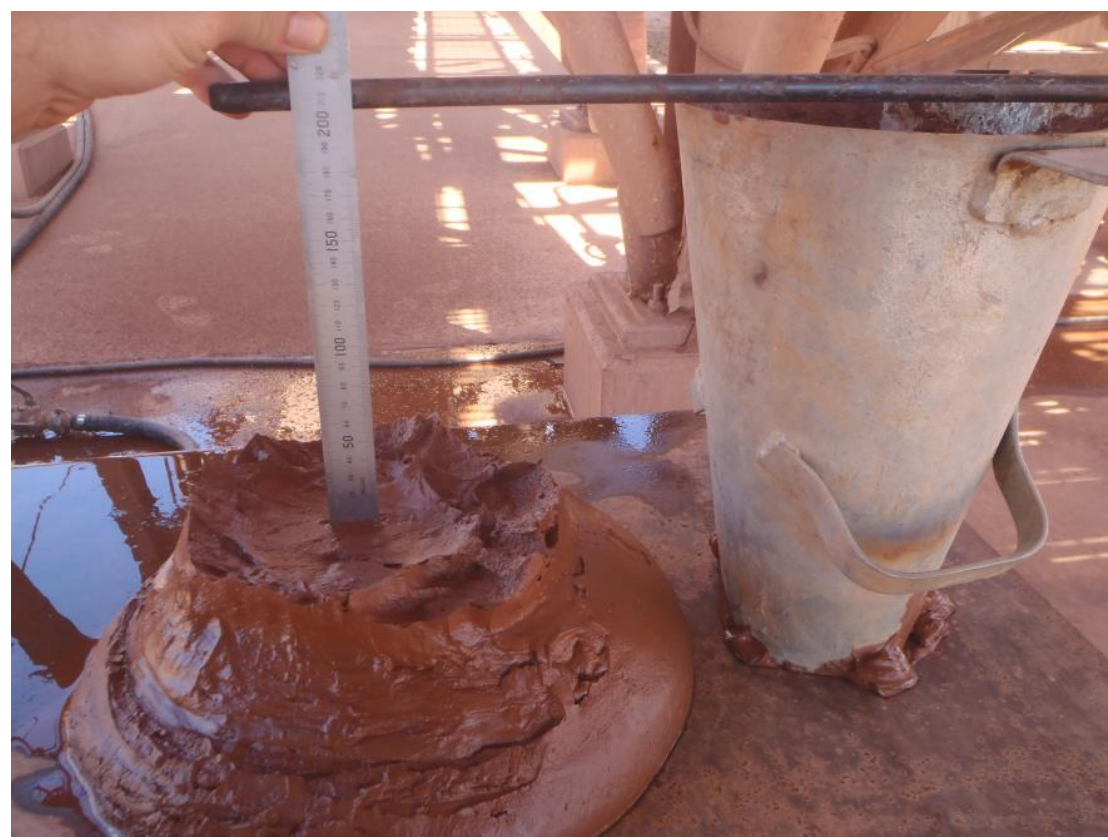

Figure 6 Picture of the $210 \mathrm{~mm}$ slump with the addition of MF505C

\section{UCS Values Field Trials}

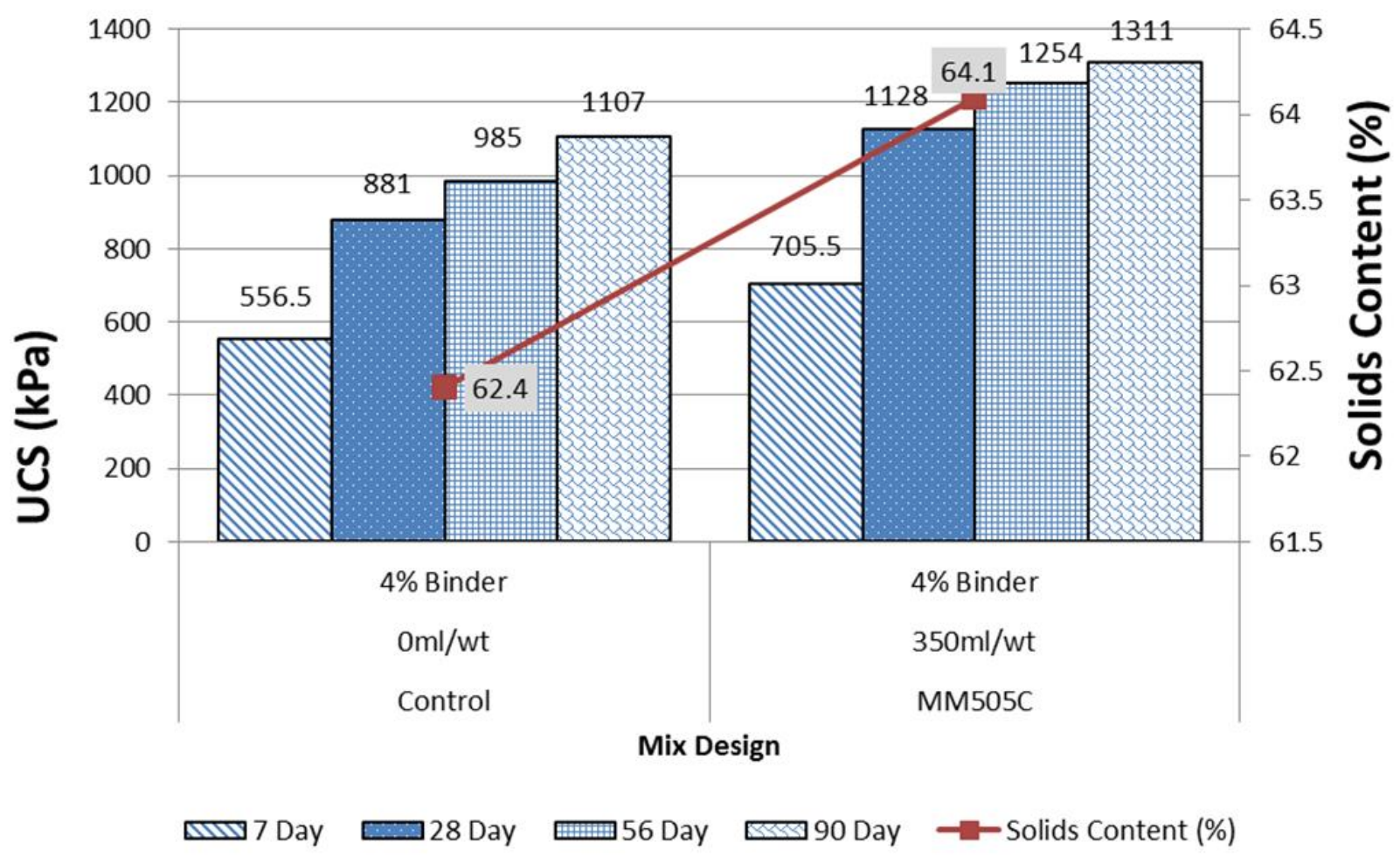

Figure 7 UCS values from fields trials

Comments on results:

The mix with $4 \%$ binder content with the MF505C trial allowed the solids to be increased by $1.7 \%$, therefore increasing the UCS results by $149 \mathrm{kPa}$ for the 7th day, $247 \mathrm{kPa}$ for the 28th day, $269 \mathrm{kPa}$ for the 56th day and $204 \mathrm{kPa}$ for the 90th day. These are significant amounts. Further binder optimisation could be done, while still remaining within geotechnical UCS requirements for the specified stope. 


\subsection{Field trial}

Objectives:

- Obtain samples of control mix at $2.5 \%$ binder.

- Reduce binder content to $2.25 \%$ with MF505C take UCS samples.

- Slump paste before casting cylinders.

The following parameters were observed:

- Pressure in PI1020 sensor increased by $1,248 \mathrm{kPa}$ when the MF505C was no longer added to the mix.

- Borehole friction increased by $4.05 \mathrm{kPa}$ when MF505C removed.

- An increase of $3 \mathrm{~m}^{3} / \mathrm{hr}$ with raw water when MF505C removed.

- Solids had to be decreased by $2 \%$ when MF505C removed.

- Slump decreased by $60 \mathrm{~mm}$ with MF505C removed.

Table 2 Summary of results from field trial MF505C at $4 \%$ binder

\begin{tabular}{cccc}
\hline Trial identification & $\mathbf{5 0 5 C}$ & Control & Control \\
\hline Time & $4.15 \mathrm{pm}$ & $4.45 \mathrm{pm}$ & $5.35 \mathrm{pm}$ \\
Binder content $(\%)$ & 2.25 & 2.5 & 2.5 \\
MasterRoc MF505C (ml/wt) & 400 & 0 & 0 \\
Ambient temperature $\left({ }^{\circ} \mathrm{C}\right)$ & 43.5 & 42.3 & 42.3 \\
Paste temperature $\left({ }^{\circ} \mathrm{C}\right)$ & 32.7 & 31.5 & 31.5 \\
Slump $(\mathrm{mm})$ & 220 & 160 & 160 \\
Moisture $(\%)$ of tailings & 11.30 & 11.30 & 11.30 \\
Solids (\%) of paste $(\mathrm{Citect})$ & 64.50 & 64.50 & 62.50 \\
P1 pressure $(\mathrm{kPa})$ & 2177 & 3425 & 2198 \\
Borehole friction $(\mathrm{kPa})$ & 7.15 & 11.2 & 7.2 \\
\hline
\end{tabular}




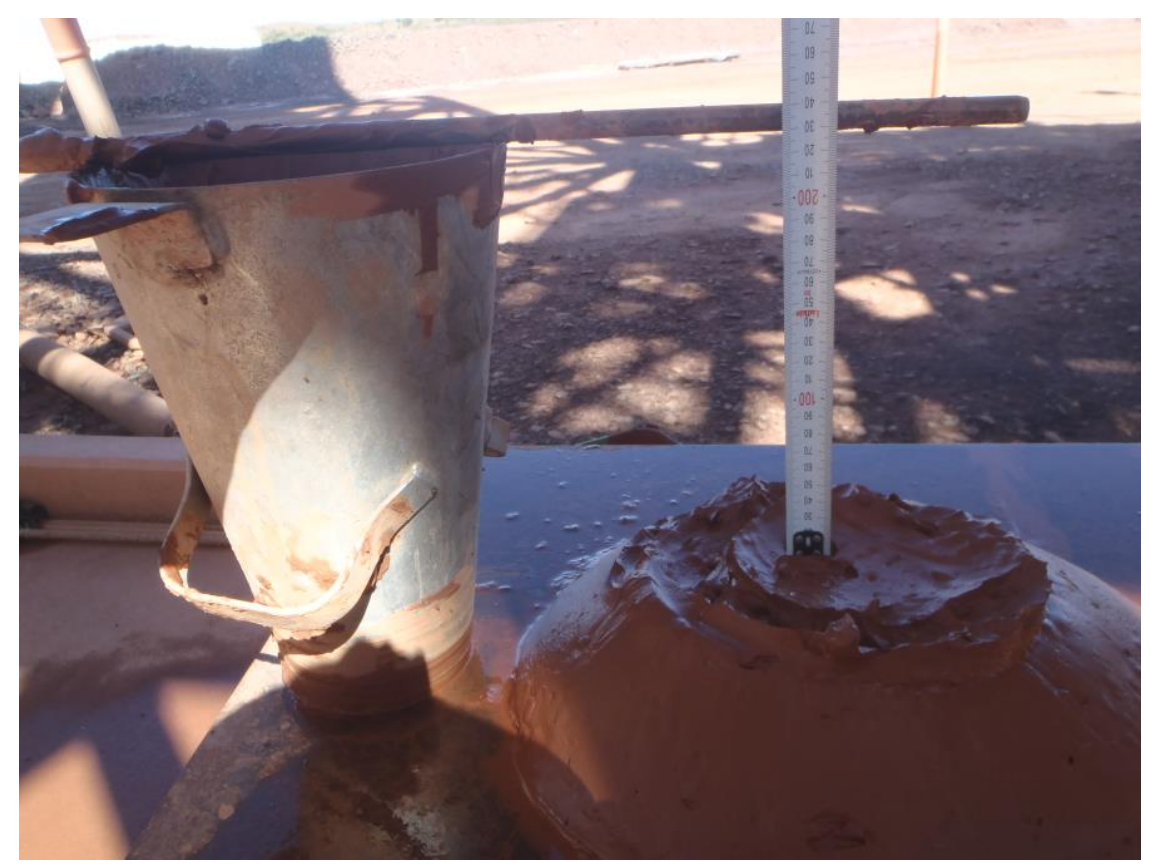

Figure 8 Picture of the slump at $220 \mathrm{~mm}$ with MF505C

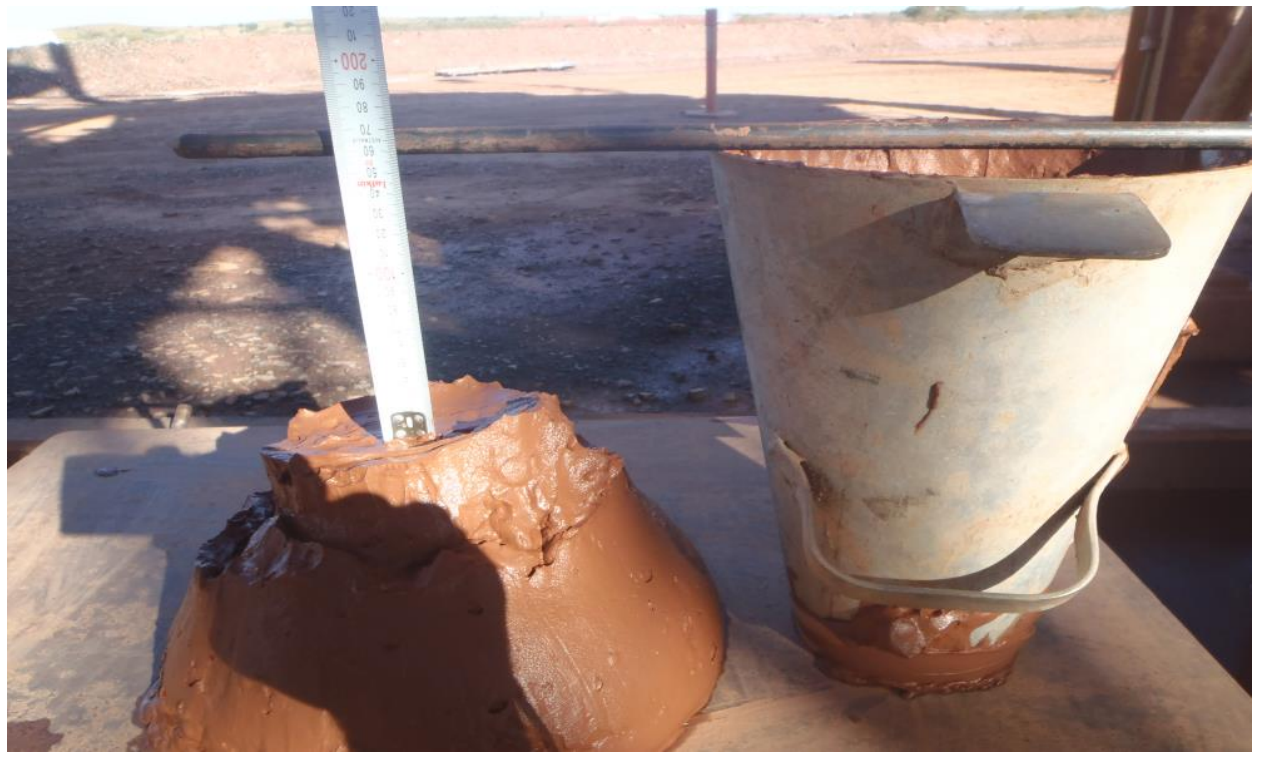

Figure 9 Picture of the slump at $160 \mathrm{~mm}$ when the MF505C was removed 


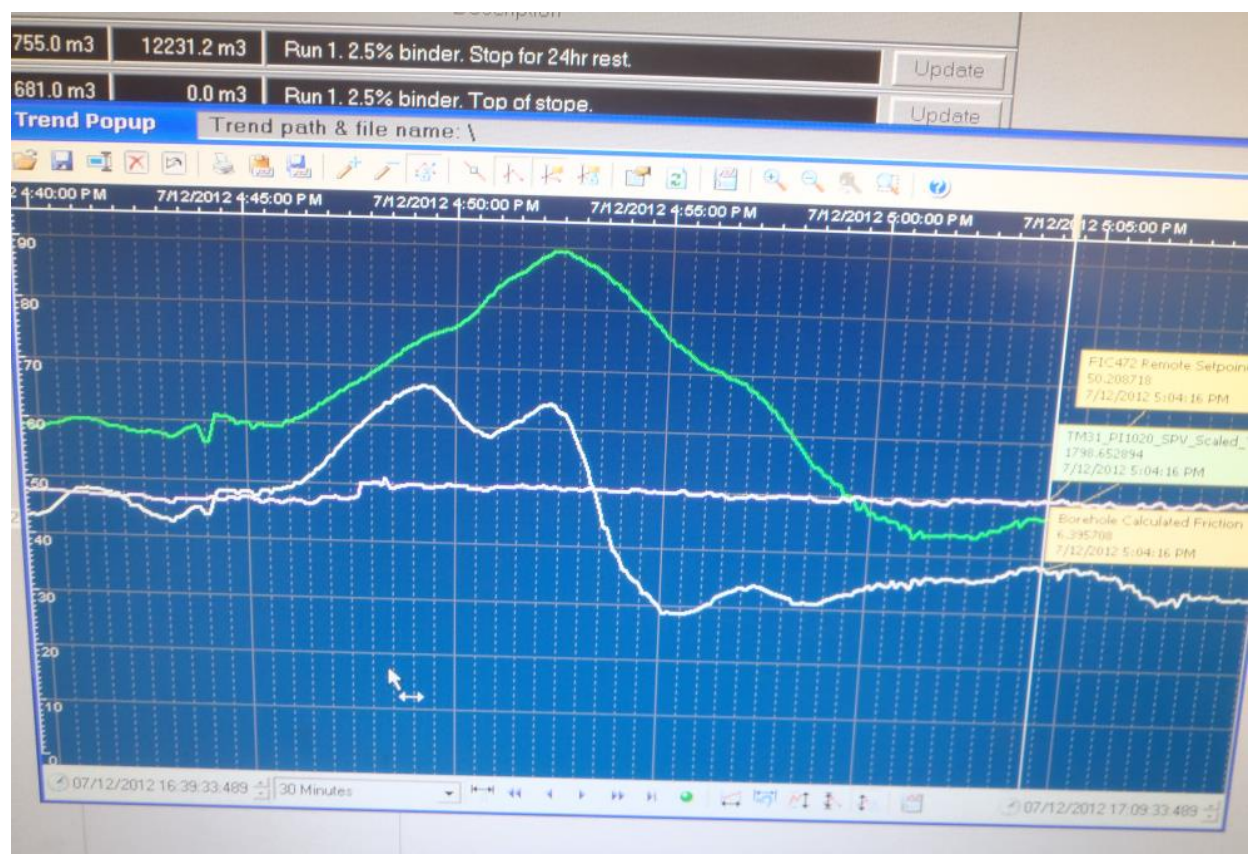

Figure 10 Screenshot showing an increase in pipe pressures (green), borehole friction (middle white) and raw water, when admixture turned off, before solids reduced

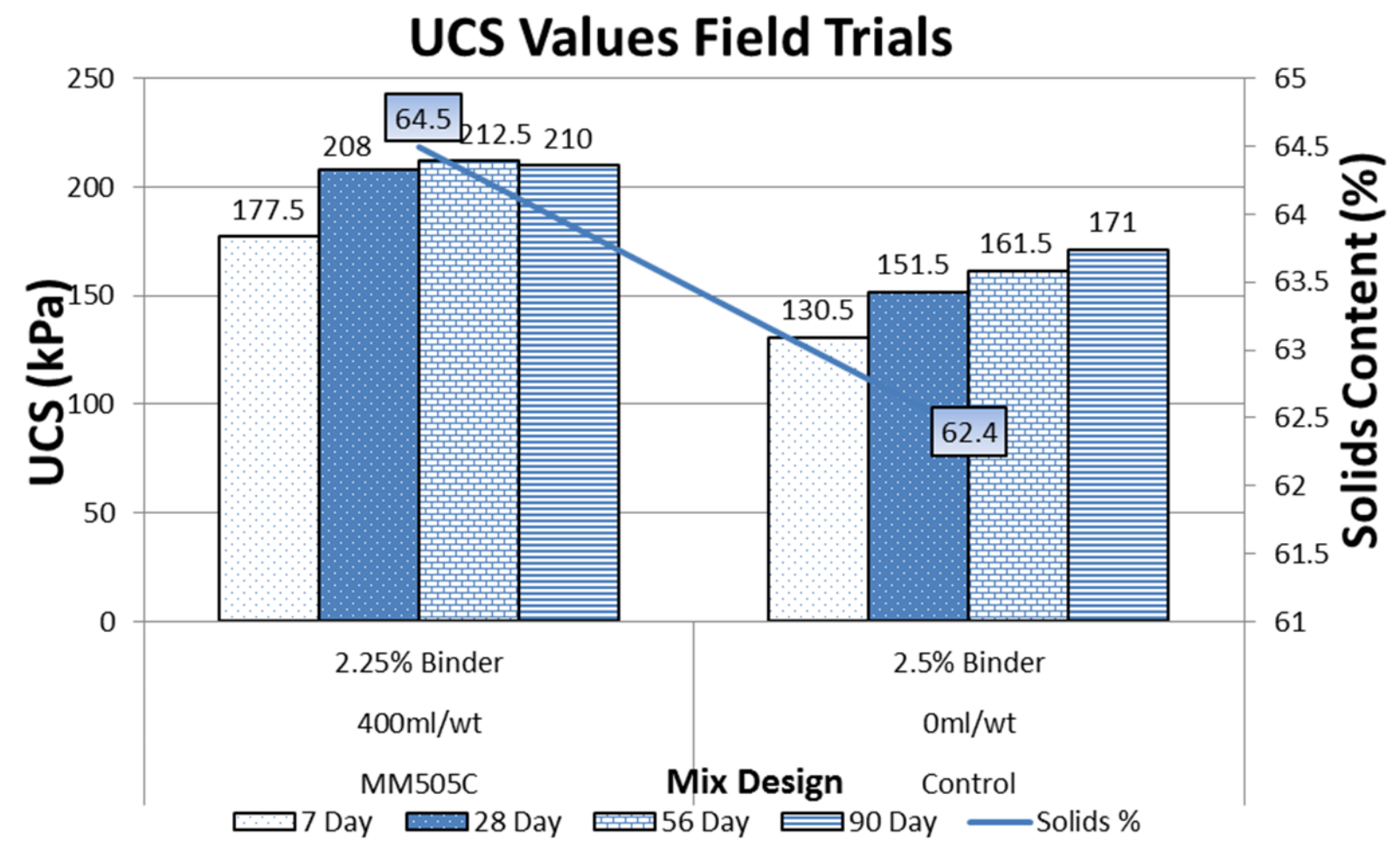

Figure 11 UCS values from fields trials

Comments on results:

The field trial indicated that the plant can run on 2.25\% binder with MF505 and obtain higher UCS results than at $2.5 \%$ binder with no admixture. This is attributed to a solids increase of $2 \%$, while maintaining workability for pipe transport. 


\section{Conclusion}

- With the introduction of the MF505C the solids content could be lifted significantly to operate at optimum pressures and densities.

- Pressures throughout the paste fill line reduced with the inclusion of the MF505C.

- Due to the increase in solids, the raw water usage was reduced. Water is a premium commodity out in the Tanami and any reduction is beneficial.

- When admixture was included in the mix it was noticed the plant ran more consistently especially when running on oversize tailings. The admixture assists in normalising the peaks and troughs, caused by variable feed and moisture contents.

- Slump results demonstrate the affect MF505C has on increasing the flowability of the mix.

- Higher UCS results were obtained with the introduction of MF505C, and higher solids content, this should allow cement content to be reduced and still obtain/maintain desired strengths.

- Plant throughput can be increased due to the rheological affects brought about by the MF505C admixture, increasing flowability etc.

- Ultimately, the chemical technology shows that it can increase solids content, increase flow, increase strengths and reduce binder contents. 